\title{
Spectroscopic and thermal degradation studies of novel hybrid polymer based on sodium polyphosphate - polystyrene
}

\author{
Driss Rair, Halima El Aadad, Touria Jermoumi and Abdelkrim Chahine * \\ Laboratory of physico-chemistry of vitreous and crystallized materials (LPCVCM), Faculty of Science, Ibn \\ Tofail University, BP 133, Kenitra14000, Morocco
}

\begin{abstract}
We have synthesized by the hydrophobic effect a new hybrid polymer material (HP) composed of segments of different solubility: polystyrene (hydrophobic) and sodium metaphosphate (hydrophilic). The structure and thermal stability of these hybrid materials were investigated and compared to the starting materials using X-ray diffraction (XRD), ${ }^{31} \mathrm{P}$ Nuclear Magnetic Resonance, Raman spectroscopy and thermogravimetric analysis (TGA).
\end{abstract}

The structure of the hybrid material consists of a mixture of phosphate compounds resulting from the hydrolysis of $\mathrm{NaPO}_{3}$. The phosphate groups have probably formed hydrogen bonds with aromatic $\mathrm{CH}$. Furthermore, the delocalization of the electrons in the aromatic group generates negative poles that can interact with the positively charged $\mathrm{Na}$ ion, forming a cation- $\pi$ interaction.

The thermal characterization of these hybrids shows a clear improvement of the thermal property. TGA results show that phosphates increase HP residues yields at $600{ }^{\circ} \mathrm{C}$. Thus, Raman spectroscopy results provide evidence for the formation of residues having an aromatic phosphocarbon and an aromatic graphitic structure.

Keywords: Hybrid polymer; hydrophobic effect; Raman spectroscopy; Thermal analysis; Phosphocarbon residue.

\section{Introduction}

The incorporation of phosphorus groups into a polystyrene matrix represents an important challenge from both the fundamental and the applied parts. These phosphoric polymers, such as polystyrene based barium phosphate and polystyrene based $\mathrm{Cu}_{3}\left(\mathrm{PO}_{4}\right)_{2} / \mathrm{Ni}_{3}\left(\mathrm{PO}_{4}\right)_{2}$, are mainly used in membrane technology for ion exchange filtration and bacterial removal ${ }^{1,2}$. Other authors have studied additives like triethylphosphate (TEP) and diethylphosphonate (DEEP) ${ }^{3}$, aluminium hypophosphate (AP) ${ }^{4}$ and $\alpha$-zirconium phosphate $(\alpha-\mathrm{ZrP}){ }^{5}$ in polystyrene to develop new flame-retardants. In electrochemistry Y.Q. Qiao and al. ${ }^{3}$ prepared a cathode based on carbon/ $/ \mathrm{Li}_{3} \mathrm{~V}_{2}\left(\mathrm{PO}_{4}\right)_{3}$, using polystyrene as a carbon source that is produced by the pyrolysis of the polymer.

In such systems, the affinity of the matrix with the charge is very low or non-existent, as it is the case for the phosphate (polar) introduced into a polymer (nonpolar), the majority of the work has been carried out in organic solvent, or by intercalation of the polymer either in molten state ${ }^{1}$, or in situ polymerization ${ }^{6,7}$. Nevertheless, synthesizing these hybrid materials in the aqueous phase remains a challenge.

*Corresponding author : Abdelkrim Chahine

Email address : abdelkrim.chahine@uit.ac.ma DOI: http://dx.doi.org/10.13171/mjc751912050915ac
Raman spectroscopy is well adapted and recommended by several authors to study covalent bonds such as $\mathrm{C}-\mathrm{C}$ bonds in polymers ${ }^{8}$ Clarkson and Bowley have normalized the intensity of the band to $1632 \mathrm{~cm}^{-1}$ (vibrations of the $\mathrm{C}=\mathrm{C}$ Vinyl styrene) by that at $1602 \mathrm{~cm}^{-1}$ (vibrations of the $\mathrm{C}=\mathrm{C}$ bonds of the aromatic ring) ${ }^{9}$, in order to monitor the variation in the styrene monomer concentration. It stays relevant to examine while studying the thermal degradation of polymers, the degradation residues by this technique that gives well-identifiable Raman spectra, such as the $\mathrm{D}$ band of disorder emerging at $\sim 1350 \mathrm{~cm}^{-1}$, and the band $\mathrm{G}$ of graphitic origin at $\sim 1580 \mathrm{~cm}^{-1}$.

In this paper, $\mathrm{NaPO}_{3} /$ polystyrene hybrid polymers were prepared by hydrophobic effect. This method offers several advantages allowing economic applications: simplicity of synthesis, work with water as a solvent, the use of inexpensive products sodium polyphosphate (SPP) or Graham's salt. Also, SPP is used as a flame retardant in many applications such as paints and coatings, and in a variety of polymers, where SPP is part of intumescent systems. This work aims to study the impact of fire retardant of SPP on the fire retardant characteristics of Polystyrene.
Received September 16, 2018

Accepted October 29, 2018

Published December 5, 2018 


\section{Experimental details}

\section{Preparation of polystyrene}

Styrene (Fluka; 104.15; > 99\%) was washed with aqueous $\mathrm{NaOH}$ to remove inhibitors. $1 \%$ of the initiator (Azobisisobutyronitrile AIBN) was added, and the mixture was heated at $70{ }^{\circ} \mathrm{C}$ for 35 minutes. The polymer obtained remained dissolved in the monomer and formed a single organic phase $\left(\varphi_{\text {or }}\right)$ to which $10 \mathrm{ml}$ of the methanol was added.

\section{Preparation of $\mathrm{NaPO}_{3} /$ polystyrene hybrid polymers}

In this case, an aqueous solution $\left(\varphi_{\mathrm{aq}}\right)$ of the sodium metaphosphate $\left(\mathrm{NaPO}_{3}\right.$ extra pure; RiedeldeHaën) at various ratios was added to the obtained organic phase $\left(\varphi_{\mathrm{or}}\right)$ (Tab.1), these two phases were mixed then stirring in methanol for $10 \mathrm{~min}$ and at room temperature. This system, non-polar polymer cluster together and exclude polar molecules, where the two phases are separated by the hydrophobic effect ${ }^{10}$. Thus, the gel formed is recovered and dried at $50{ }^{\circ} \mathrm{C}$ for 24 hours.

Table 1. Composition of recipes to prepareneatPSt and $\mathrm{PSt} / \mathrm{NaPO}_{3}$ hybrids.

\begin{tabular}{|c|c|c|c|}
\hline Qor & $\varphi$ aq & & \\
\hline Styrene (g) / AIBN (g) & $\mathrm{NaPO}_{3}(\mathrm{~g}) / \mathrm{H}_{2} \mathrm{O}(\mathrm{mL})$ & $\mathrm{CH}_{3} \mathrm{OH}(\mathrm{mL})$ & $\mathrm{Na} / \mathrm{St}$ \\
\hline $2 / 0.02$ & $0 / 0$ & 10 & 0 \\
\hline $2 / 0.02$ & $0.20 / 10$ & 10 & 0.10 \\
\hline $2 / 0.02$ & $0.50 / 10$ & 10 & 0.25 \\
\hline
\end{tabular}

\section{Characterization}

X-ray powder diffraction (XRD) patterns were taken to analyze the crystal structures of phosphates, using a Philips (X'PERT- PRO) diffractometer with $\mathrm{Cu} \mathrm{K} \alpha$ radiation $(\lambda=0.1542 \mathrm{~nm}$ at $40 \mathrm{kV}$ and $40 \mathrm{~mA})$ at a scanning rate of $4 \% \mathrm{~min}$, ranging from 10 to $70^{\circ}$. Liquid NMR was performed using a Bruker Advance 300 spectrometer equipped with a standard broadband $5 \mathrm{~mm}$ probe head, operating at $121.49 \mathrm{MHz}$ phosphorus frequency. Hybrid polymers HP were finely crushed and dissolved in a deuterium oxide at a temperature of $27 \pm 1{ }^{\circ} \mathrm{C}$ for approximately $20 \mathrm{~min}$ before the measurement.

The Raman spectra were measured in the range 200- $4000 \mathrm{~cm}^{-1}$ with a Renishaw-branded Raman spectrometer, type RM 1000, coupled to an internal laser $\mathrm{He}-\mathrm{Ne}(20 \mathrm{~mW})$ using the $632.8 \mathrm{~nm}$ line.

Thermo-gravimetric analysis (TGA) was carried out using a thermobalance (SETARAM type Labsys) from room temperature to $600^{\circ} \mathrm{C}$, at a rate of $5^{\circ} \mathrm{C} / \mathrm{min}$ in a continuous nitrogen flow.

\section{Results and Discussion}

\section{Precursors structure Polystyrene}

The polystyrene was prepared by radical polymerization of styrene monomer. The theoretical molar mass $\left(\mathrm{M}_{\mathrm{th}}\right)$ of the polymer could be defined with supposing that all the initiators have reacted and used the conversion rate:

$$
\mathrm{M}_{\mathrm{th}}\left(\mathrm{g} \cdot \mathrm{mol}^{-1}\right)=\frac{\frac{\mathrm{M}_{0}}{\mathrm{I}_{0}} \cdot \mathrm{M}_{\text {monomer }} \cdot \text { conversion }}{100} \approx \mathbf{7 6 0 0}
$$

$\mathrm{M}_{0} / \mathrm{I}_{0}$ : The ratio of the amount of monomer to the amount of initiator.

$\mathrm{M}_{\text {monomère }}$ The molar mass of the monomer.
The conversion rate was determined by Raman spectroscopy (Fig.1). It is calculated by the ratio:

$\frac{\mathbf{I}_{\mathbf{a r}}^{\mathbf{1 6 0 2}}-\mathbf{I}_{\text {vin }}^{\mathbf{1 6 3 2}}}{\mathbf{I}_{\mathbf{a r}}^{\mathbf{1 6 0 2}}} \times \mathbf{1 0 0} \quad$ Conversion $=72.54 \%$

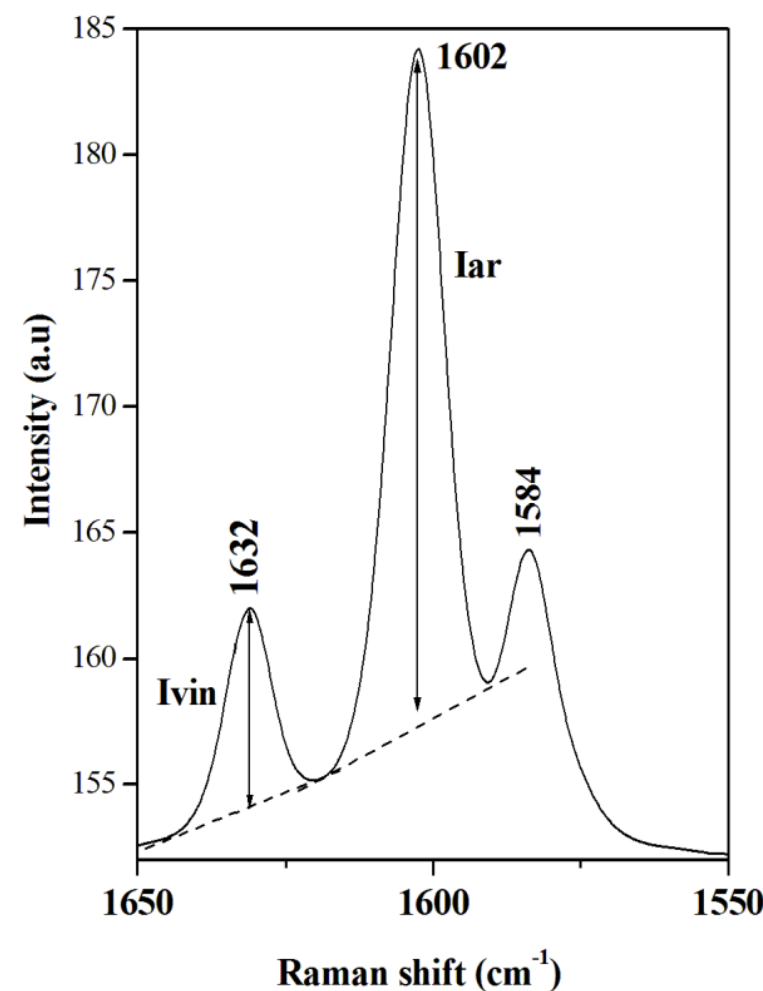

Figure 1. Determination of $I_{a r}$ and $I_{v i n}$ intensities by Raman spectroscopy

Besides Raman spectroscopy allowed us to confirm the nature of the polymer by identifying the characteristic bands of Polystyrene reported in the literature ${ }^{11}$ (Fig.2). 


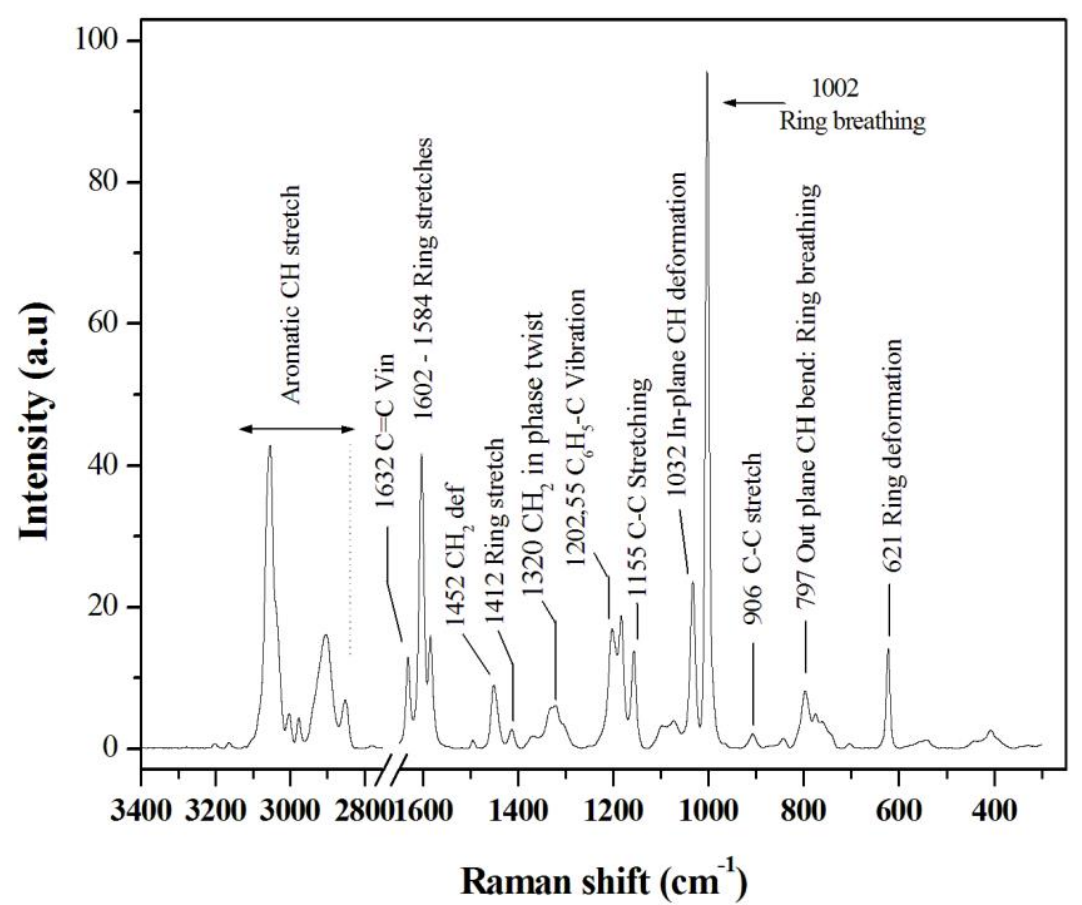

Figure 2. Assignments of the characteristic Raman peaks in polystyrene

Sodium hexametaphosphate $\mathrm{NaPO}_{3}$

Sodium hexametaphosphate of commerce is typically a mixture of polymeric metaphosphates, of which the hexamer is one, and is usually the compound referred to by this name. It is more correctly termed sodium polymetaphosphate.
The X-ray diffraction pattern shows no crystalline phases in $\mathrm{NaPO}_{3}$. Figure 3 presents the diffraction spectrum of the sample; this latter is amorphous as indicated by the absence of Bragg peaks and the presence of amorphous halos.

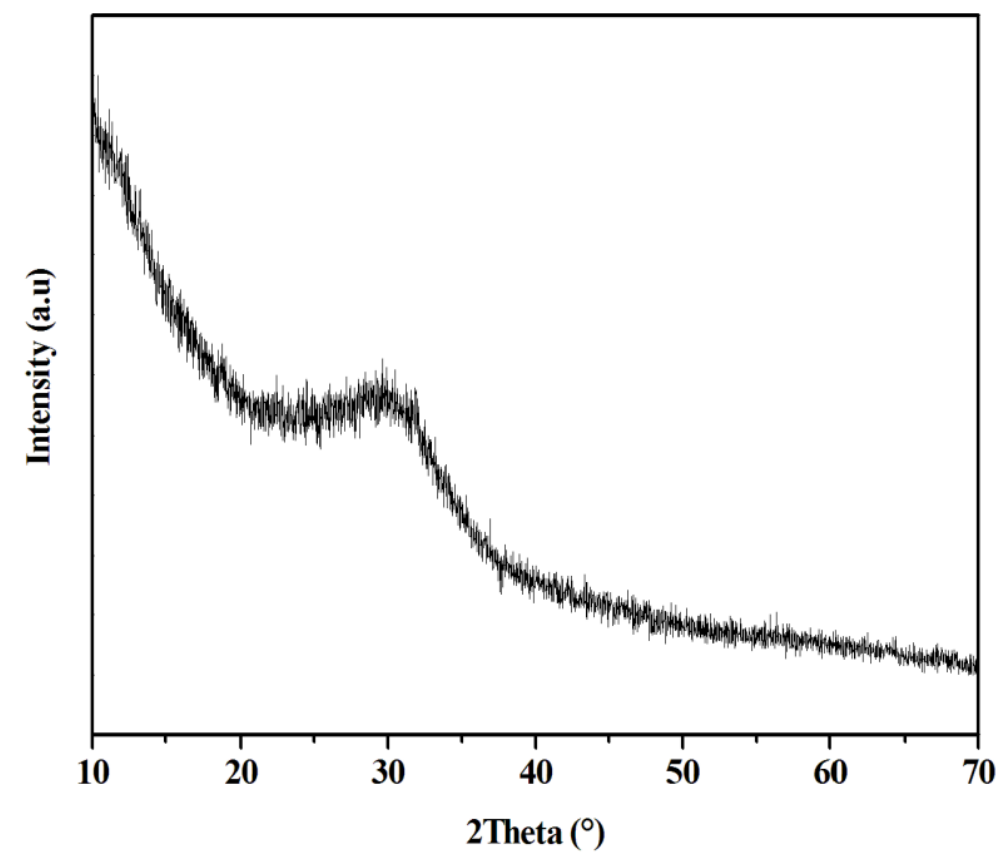

Figure 3. XRD spectra of $\mathrm{NaPO}_{3}$

The Raman spectra of $\mathrm{NaPO}_{3}$ in the frequency range between 200 and $1400 \mathrm{~cm}^{-1}$, is shown in Fig. 4 . The typical four principal groups of the stretching vibrations were observed, which are all associated with the metaphosphate structure ${ }^{12}$. 


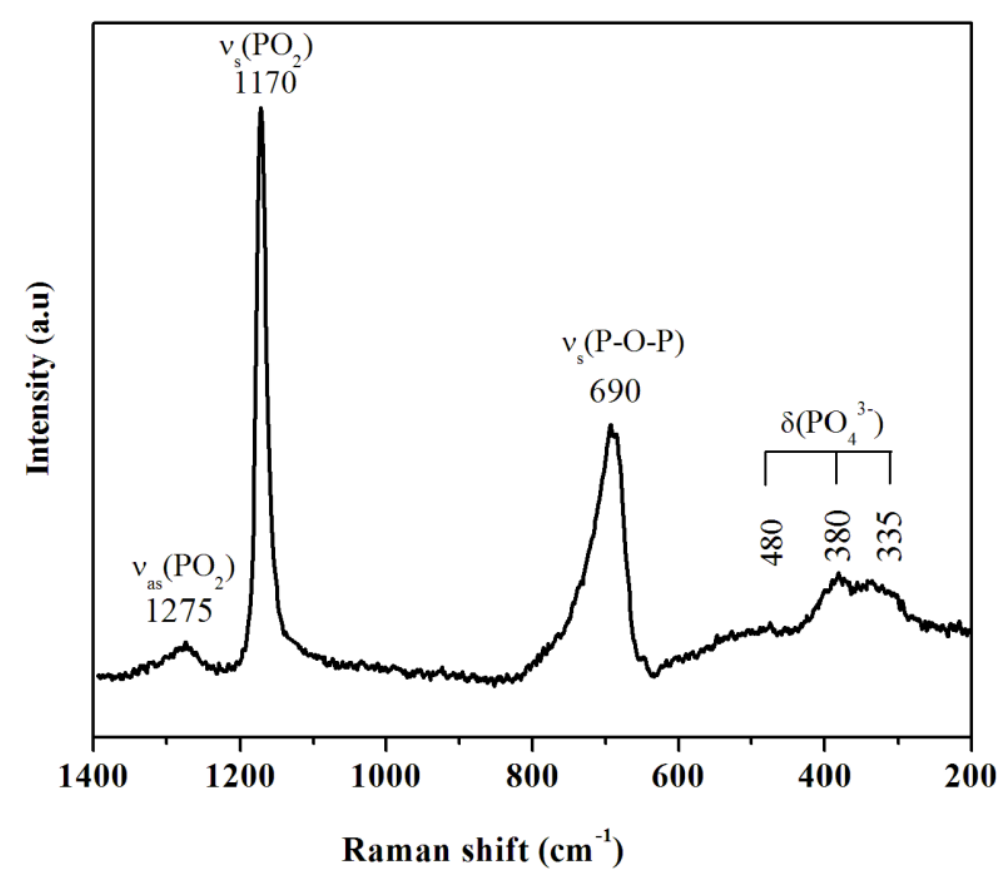

Figure 4. Assignments of the characteristic Raman peaks in $\mathrm{NaPO}_{3}$

${ }^{31} \mathrm{P}$ NMR is used to monitor hexametaphosphate hydrolysis. This analysis indicates that the hydrolysis of $\mathrm{NaPO}_{3}$ leads mainly to orthophosphate, pyrophosphate and trimetaphosphate (Fig.5).

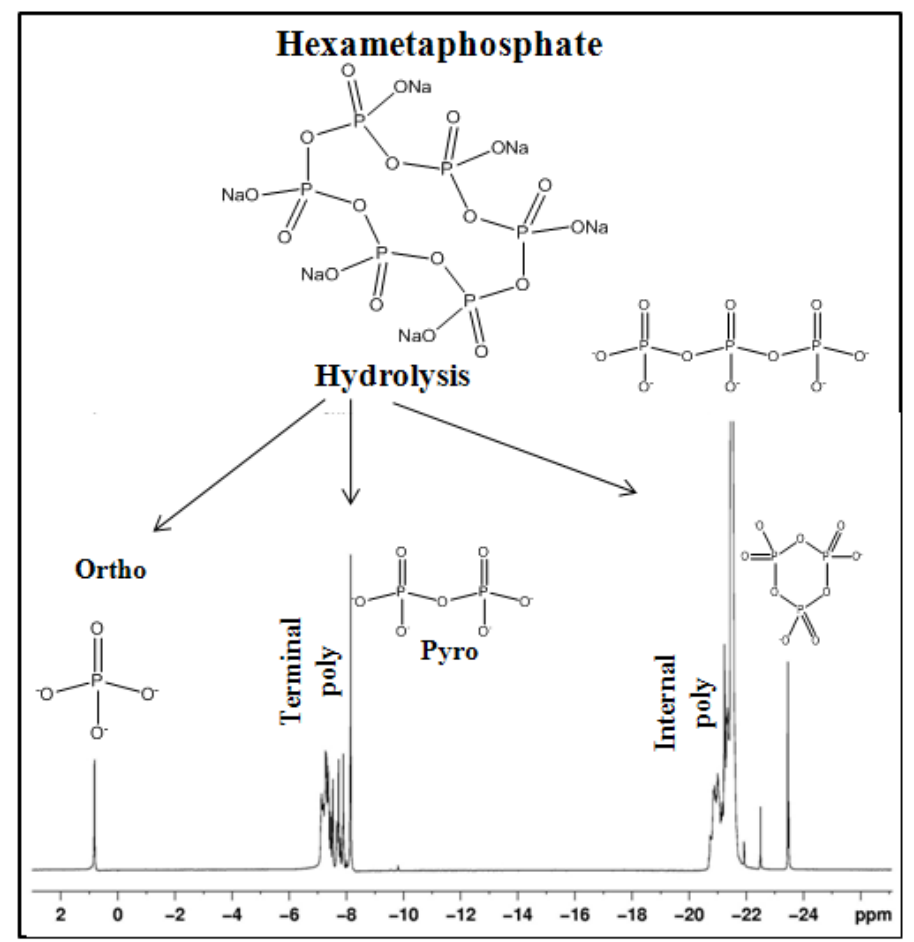

Figure 5. ${ }^{31} \mathrm{P}$ liquid NMR spectrum of hydrolyzed commercial polyphosphate $\mathrm{NaPO}_{3}$

$\mathrm{NaPO}_{3}$ /polystyrene hybrid polymers structure $X$-ray diffraction and NMR spectroscopy

The XRD pattern (Fig. 6) shows that the PSt did not reveal any discreet or sharp peaks, but a broad humps characteristic of the amorphous materials. In opposition, the spectra of HP (0.1 and 0.25$)$ (that contains phosphates) have peaks. From the XRD patterns, the crystallite size was calculated using the L. B. Scherrer formula:

$$
\Phi_{\mathrm{hkl}}=\frac{\mathrm{K} \cdot \lambda}{\frac{\mathrm{B} \cdot \pi}{180} \cdot \cos \theta}
$$

Where $\mathrm{k}=0,9$ is the order of reflection, $\lambda$ is 1.542 $\AA$, and B is the full width at half maximum (FWHM). 
$\theta:$ The angle of the most intense diffraction peak measured in degrees, and which is present in the three phosphate forms. $\mathrm{Na}_{3} \mathrm{P}_{3} \mathrm{O}_{9}, 3 \mathrm{H}_{2} \mathrm{O}$ (13-0402 ASTM),
$\mathrm{Na}_{4} \mathrm{P}_{2} \mathrm{O}_{7}, 10 \mathrm{H}_{2} \mathrm{O}$ (72-1082 ASTM) and $\mathrm{NaH}_{2} \mathrm{PO}_{4}(11-$ 0659 ASTM). The corresponding data obtained from XRD measurements are given in Table 2.

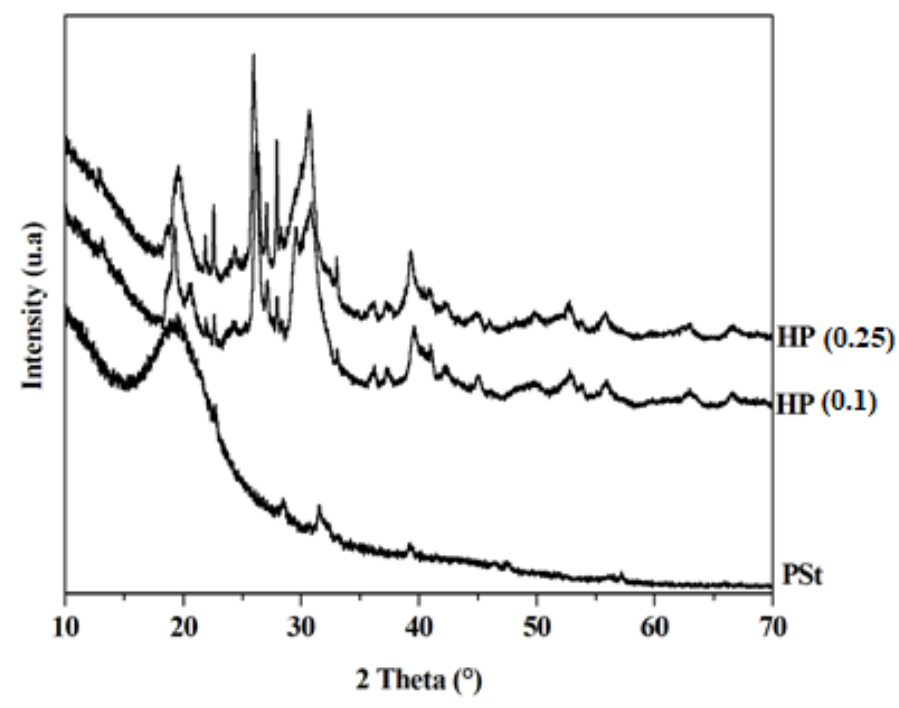

Figure 6. XRD patterns for the PSt $(0)$ and $\operatorname{HP}(0,1 \& 0,25)$

Table 2. XRD values for the HP crystallite.

\begin{tabular}{|c|c|c|c|c|}
\hline HP & Pos $\left[{ }^{\circ} 2 \mathrm{Th}\right]$ & FWHM $\left[{ }^{\circ} 2 \mathrm{Th}\right]$ & $\mathrm{d}$-spacing $[\AA]$ & $\Phi_{\text {hkl }}[\AA]$ \\
\hline 0.25 & 25.9518 & 0.1338 & 3.4334 & 610 \\
\hline 0.1 & 26.0815 & 0.1338 & 3.4166 & 610 \\
\hline
\end{tabular}

Thereby, the phosphate is incorporated in the hybrid material in the form of a mixture of phosphate compounds: orthophosphate, pyrophosphate and trimetaphosphate. This result is confirmed by ${ }^{31} \mathrm{P}$ NMR analysis in $\mathrm{D}_{2} \mathrm{O}$, and all of these results are grouped in the following Table 3.

Table 3. ${ }^{31} \mathrm{P}$ NMR chemical (121.49 MHz) shifts in $\mathrm{D}_{2} \mathrm{O}$ of $\mathrm{HP}$.

\begin{tabular}{|c|c|c|c|}
\hline HP & Orthophosphate & Pyrophosphate & $\begin{array}{c}\text { Trimetaphosphate } \\
\delta \text { ppm }\end{array}$ \\
\hline $\mathbf{0 . 1}$ & $\delta$ ppm & -9.415 & -21.327 \\
\hline $\mathbf{0 . 2 5}$ & 0.25 & -9.589 & -22.074 \\
\hline
\end{tabular}

\section{Raman Spectroscopy:}

Raman spectroscopy was used to investigate the structure of prepared samples, and the corresponding spectra are shown in Fig 7. There is no difference in the general shape of the spectra of the HP at $\mathrm{Na} / \mathrm{St}=0.1$ and 0.25 with the polystyrene matrix, so all the bands corresponding to the polystyrene are found.

The introduction of the sodium polyphosphate to the organic matrix revealed an additional band at about $\quad 744 \mathrm{~cm}^{-1}$, assigned to the symmetrical vibration of the P-O-P bridges vs (P-O-P) in the metaphosphate chains ${ }^{13,14}$.

In this study, we chose to use curve fitting to approximate the two band shapes and thereby separate the two overlapping regions. The massif towards 1000 $\mathrm{cm}^{-1}$ is subject to peak fitting by using the curve fitting software Origin /peak fitting module to resolve the curve into Gaussian bands.

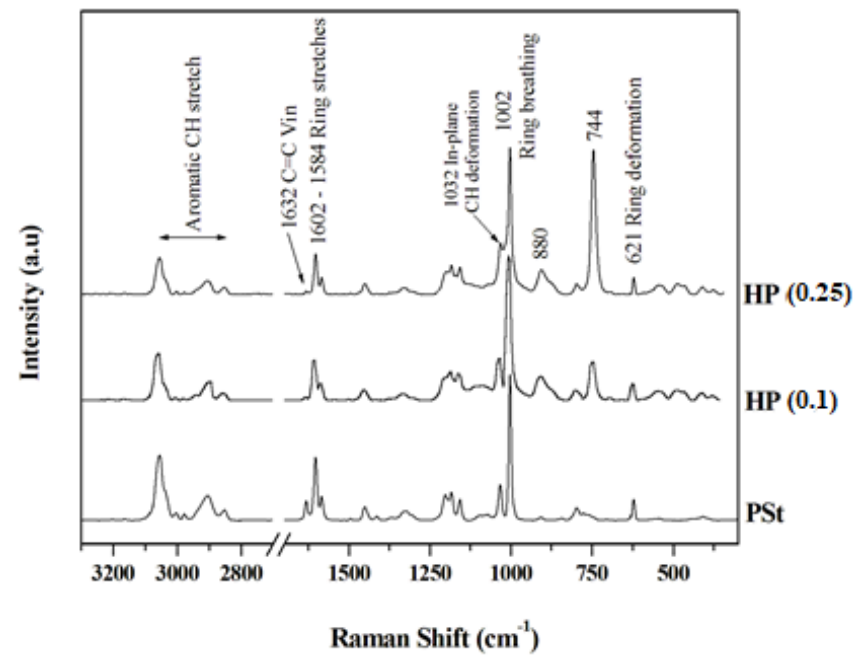

Figure 7. Raman spectrums of PSt and HP (0.1; 0.25 ) from 3300 to $300 \mathrm{~cm}^{-1}$ at room temperature 
Figure $8 \mathrm{~b}$ is shown the fitting analysis of $\mathrm{HP}$ $(\mathrm{Na} / \mathrm{St}=0,1)$ profile in the Raman spectrum; it contains four major components. They are located at $1032 \mathrm{~cm}^{-1}$ (CH deformation), $1002 \mathrm{~cm}^{-1}$ (ring breathing), $906 \mathrm{~cm}^{-1}$ (Aromatic C-Cst), and $880 \mathrm{~cm}^{-1}$ $(\mathrm{P}-\mathrm{OH})^{15}$. On the other hand, curve-fitting analysis of the same region of $\mathrm{HP}(\mathrm{Na} / \mathrm{St}=0,25)$ profile in Raman spectra identified five components (Fig.8c). In addition to the four bands previously observed, the fitting analysis shows an additional band located around $1018.7 \mathrm{~cm}^{-1}$ attributed to the symmetric valence vibration of the $\mathrm{PO}_{3}$ groups ${ }^{16}$.
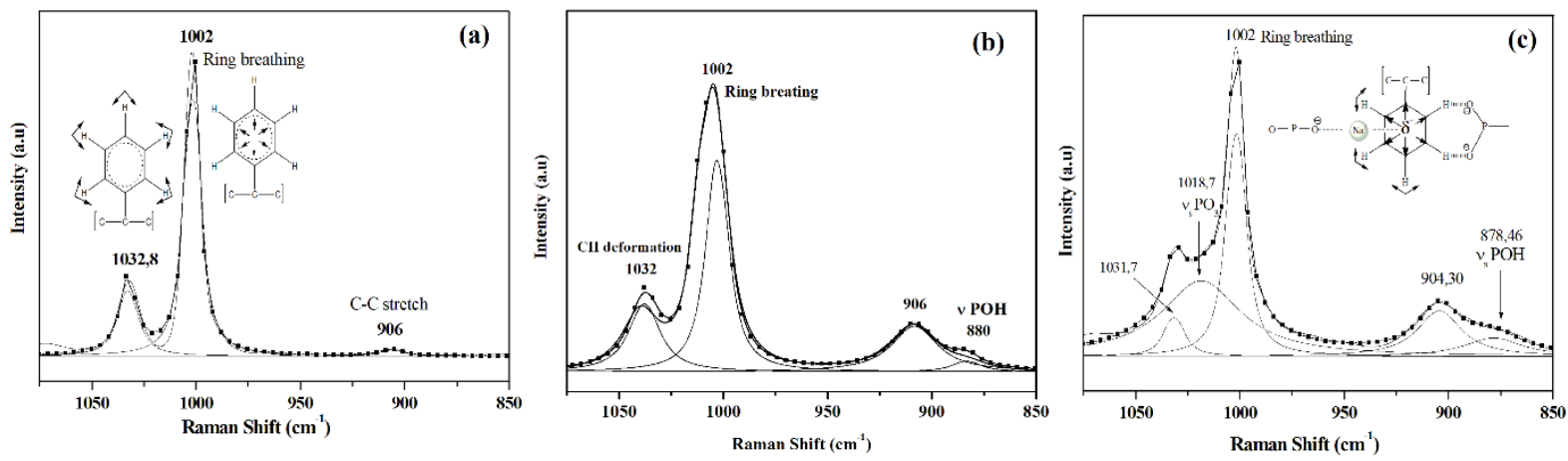

Figure 8. Fitted Raman spectrum from 1075 to $850 \mathrm{~cm}^{-1}$ at room temperature

We think that the phosphate groups have probably formed hydrogen bonds with aromatic $\mathrm{CH}$. Also, the $\pi$-electron system of an aromatic ring attracts a positive charge in the field with interaction energy comparable to that of a hydrogen bond ${ }^{17}$. All these results allowed us to outline possible interactions between the polymer matrix and sodium phosphates (Scheme.1).

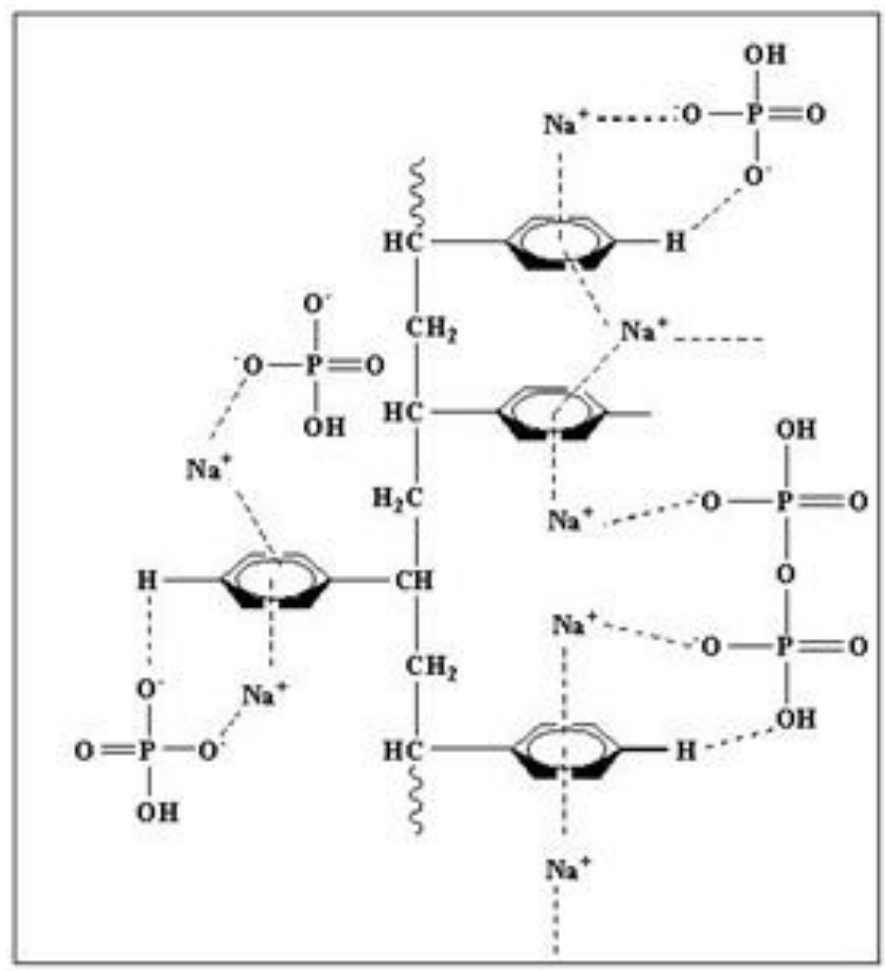

Scheme 1. Possible interactions between the polymer matrix and sodium phosphates

Thermogravimetric analysis

Thermogravimetric analysis (TGA) and differential thermogravimetric (DTG) curves of samples in a nitrogen atmosphere are shown in Fig. 9. The general shape of the thermogramspectras obtained has almost the same appearance. 

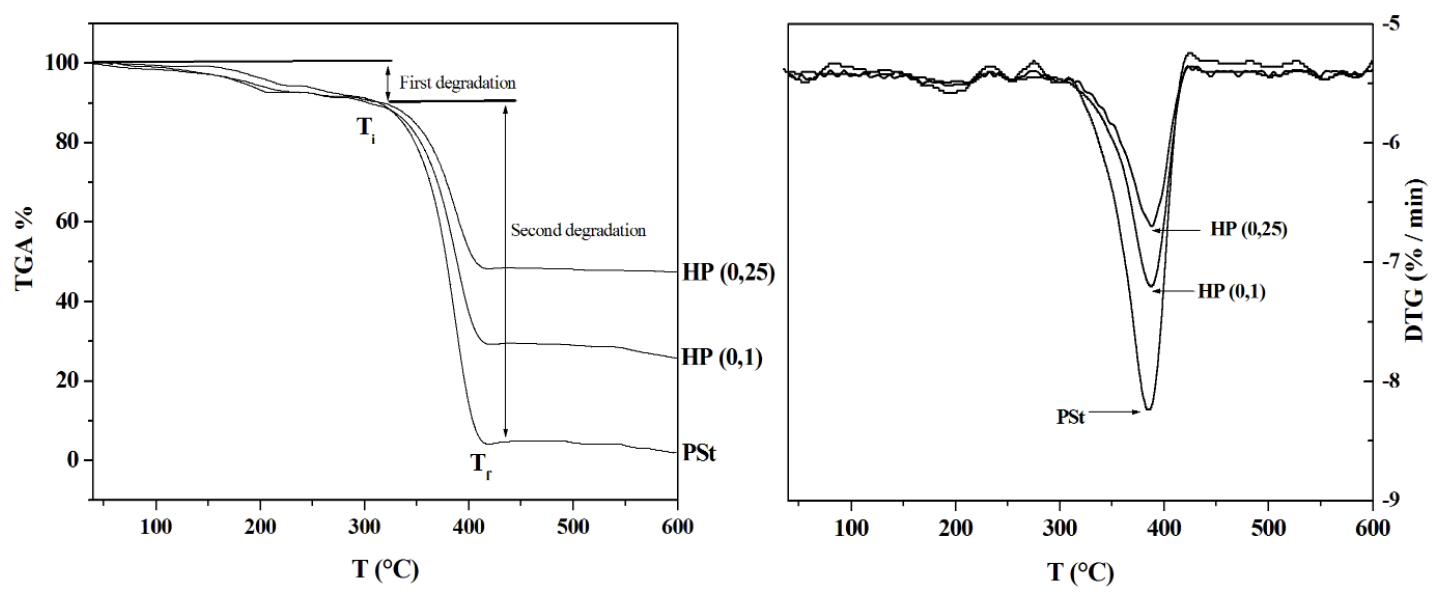

Figure 9. TG and DTG curves of PSt and $\operatorname{HP}(0,1 ; 0,25)$

The first degradation step corresponds to the removal of volatile low molar mass components and the residual non-solvent in the final product. The second mass loss begins at $T_{i}$ and ends at $T_{f}$. The main thermal characteristics of the studied materials which are extracted from thermograms (Fig.9), according to the conventional standards ${ }^{18,19}$ are classified

Table.4. Thermal properties of PSt and HP.

\begin{tabular}{|c|c|c|c|c|}
\hline sample & $\begin{array}{c}\text { Initial weight loss, } \\
\mathrm{T}_{\mathrm{i}}\left({ }^{\circ} \mathrm{C}\right)\end{array}$ & $\begin{array}{c}\text { Temp. At max. } \\
\text { degrad., } \mathrm{T}_{\mathrm{m}}\left({ }^{\circ} \mathrm{C}\right)\end{array}$ & $\begin{array}{c}\text { Final weight loss, } \\
\mathrm{T}_{\mathrm{f}}\left({ }^{\circ} \mathrm{C}\right)\end{array}$ & $\begin{array}{c}\text { Residual weight }(\%) \text { at } \\
600^{\circ} \mathrm{C}\end{array}$ \\
\hline PSt & 308 & 388 & 416 & 0 \\
\hline HP (0.1) & 315 & 386 & 420 & 22.8 \\
\hline HP (0.25) & 318 & 388 & 420 & 47.4 \\
\hline
\end{tabular}

The TGA curves show that the material decomposition begins at $308{ }^{\circ} \mathrm{C}, 315^{\circ} \mathrm{C}$ and $318^{\circ} \mathrm{C}$, respectively for PSt, HP (0.1) and HP (0.25). All these results reflect the low kinetics of the thermal degradation of these materials. The figure clearly shows that the increase in the content of inorganic compounds (sodium phosphates) improves the thermal resistance of the organic compound, thus (Ti) increases from $308^{\circ} \mathrm{C}$ for the PSt to $318^{\circ} \mathrm{C}$ for the

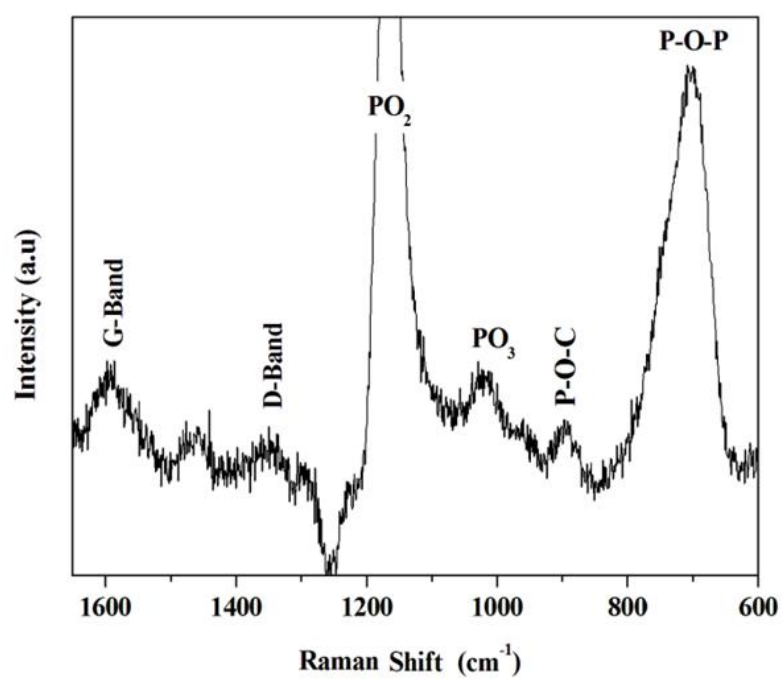

Figure 10. Raman spectra of the pyrolysis residue of $\mathrm{HP}(0.25)$ in region $1650-600 \mathrm{~cm}^{-1}$ at $600{ }^{\circ} \mathrm{C}$ hybrid (0.25). It means that the polymer hybrid $(0.25)$ is more thermally stable than the other materials.

\section{Graphitized char structure}

The Raman spectroscopy was also used to investigate the graphitic structure of char residue, of HP $(0,25)$ treated at $600{ }^{\circ} \mathrm{C}$. The region of the spectrum from 600 to $1650 \mathrm{~cm}^{-1}$ obtained using a 632,8nm excitation is displayed in Fig. 10.

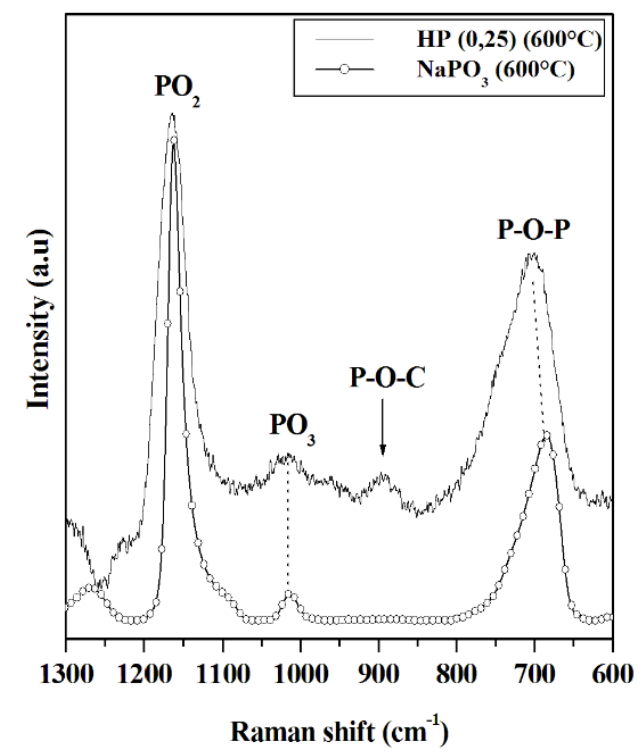

Figure 11. Raman spectra of the pyrolysis residues of $\mathrm{NaPO}_{3}$ and $\mathrm{HP}(0.25)$ at $600{ }^{\circ} \mathrm{C}$ 
The first region of the spectrum from 1300 to 600 $\mathrm{cm}^{-1}$ are shown in Fig. 11; it is observed that besides the formation of a metaphosphate structure, the shape of the spectra at is typical of that obtained by $\mathrm{NaPO}_{3}$ at $600{ }^{\circ} \mathrm{C}$. The new band at $895 \mathrm{~cm}^{-1}$ observed in the spectrum of HP $(0.25)$ can be attributed to the generation of $\mathrm{P}-\mathrm{O}-\mathrm{C}$ during the combustion process.

The second region of the spectrum from 1300 to $1650 \mathrm{~cm}^{-1}$ is shown in Fig. 12. Deconvolution of the signal into three peaks is proposed to using the curve fitting software Origin 8.0. This spectrum shown two broad peaks $\left(\mathrm{FWHM} \approx 78 \mathrm{~cm}^{-1}\right.$ ) at $1586 \mathrm{~cm}^{-1}$ (labeled G) and $1365 \mathrm{~cm}^{-1}$ (labeled D) ${ }^{20,21,22}$. The D peak represents the disordered graphite, such as the clusters of hexagonal rings. The $G$ peak has been assigned to the ordered graphite which originates from the ordered hexagonal rings. The band observed at $\sim 1460 \mathrm{~cm}^{-1}$ is assigned to a trans-polyacetylene phase ${ }^{23,24}$, The formation of the graphitized char during the thermal degradation improves the inhibition of the heat transfer because it is very stable at high temperature ${ }^{25}$. Based on the results of TG and Raman tests, the charring process of $\mathrm{HP}\left(\mathrm{PS} / \mathrm{NaPO}_{3}\right)$ system is presented in Scheme 2.

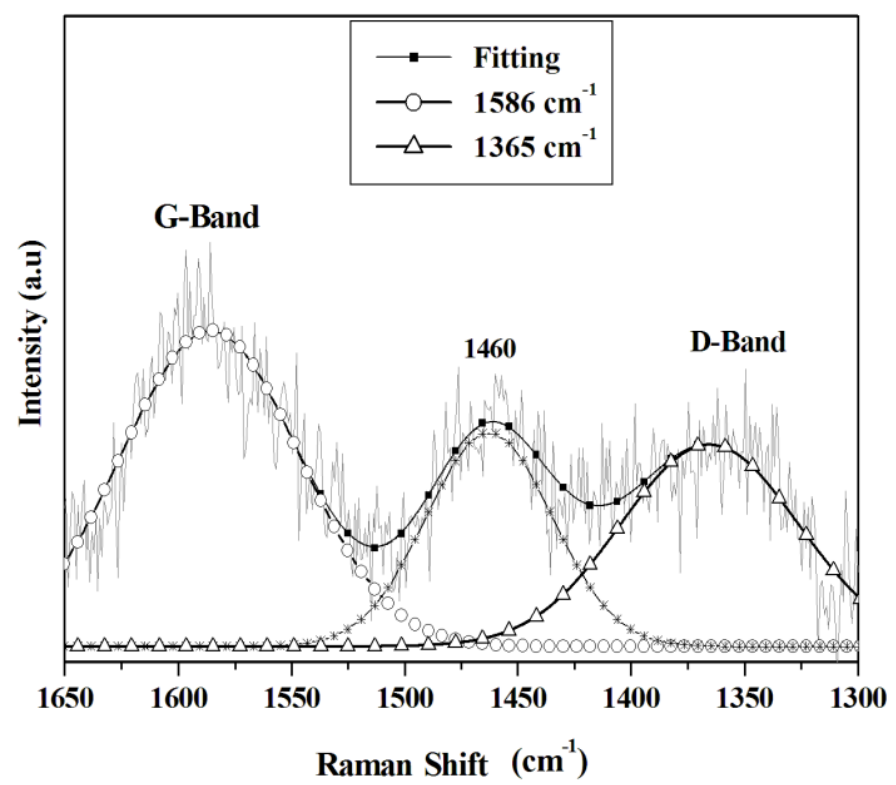

Figure 12. $1650-1300 \mathrm{~cm}^{-1}$ fitting Raman spectra of the pyrolysis residue of $\mathrm{HP}(0.25)$ in the region at $600{ }^{\circ} \mathrm{C}$

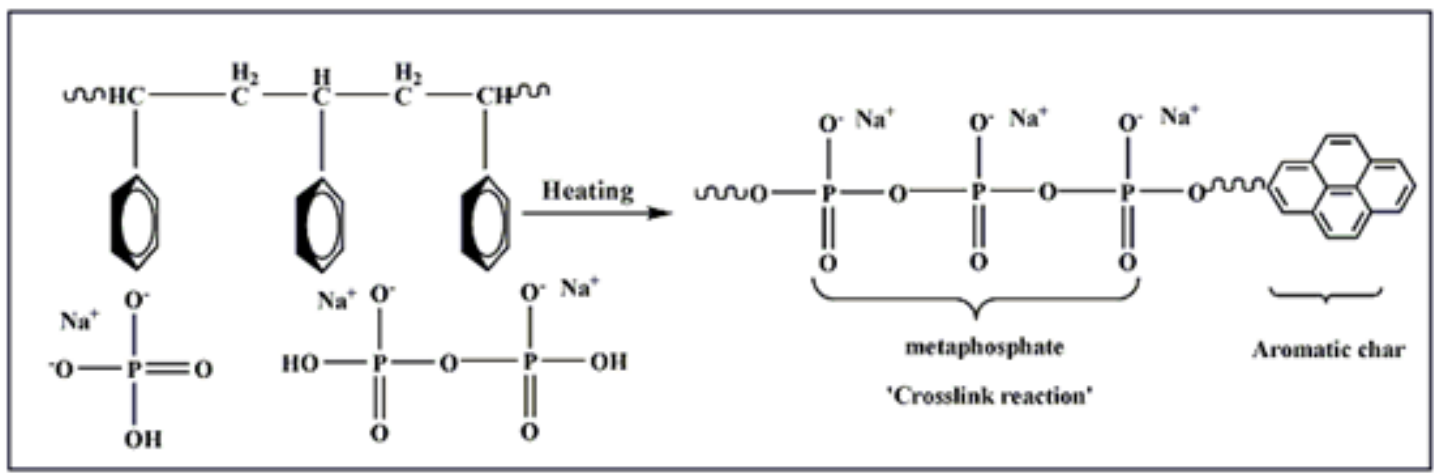

Scheme 2. Degradation process of (PSt/ Phosphate) system

\section{Conclusion}

By hydrophobic effect, (Polystyrene/ $\mathrm{NaPO}_{3}$ ) hybrids were successfully synthesized and characterized. $\mathrm{NaPO}_{3}$ solution acted as a hydrophilic agent in the preparation of hybrid polymer (HP). The XRD and ${ }^{31} \mathrm{P}$ NMR spectroscopy show that HP consists of a mixture: orthophosphate, pyrophosphate and trimetaphosphate. The Raman spectroscopy is used to investigate the structural modifications of HP. This reveals that the phosphate groups have probably formed hydrogen bonds with aromatic $\mathrm{CH}$. The TGA results showed that the thermal stability and char yields of the hybrids were significantly enhanced in comparison with pure PSt. Thus, the results of Raman spectroscopy confirm the graphitization of the residual char.

\section{References}

1- M. Mujahid, A. Khan, Rafiuddin, Inamuddin, Journal of Industrial and Engineering Chemistry, 2013, 19, 120-128. 
2- M. Arsalan, Rafiuddin, Journal of Industrial and Engineering Chemistry, 2014, 20, 35683577.

3- Y.Q. Qiao, X.L. Wang, Y. Zhou, J.Y. Xiang, D. Zhang, S.J. Shi, J.P.

Tu, ElectrochimicaActa, 2010, 56, 510-516.

4- A. Bhide, K. Hariharan, Journal of Power Sources, 2006, 159, 1450-1457.

5- A. Bhide, K. Hariharan, European Polymer Journal. 2007, 43, 4253-4270.

6- N. Nabih, U. Herrmann, G. Glasser, I. Lieberwirth, K. Landfester, A. Taden, Progress in Organic Coatings, 2013, 76, 555-562.

7- M.L. Renier and D.H. Kohn, Journal of Biomedical Materials Research, 1997, 34, 95-104.

8- H.G.M. Edwards, D.R. Brown, J.A. Dale, S. Plant, Vibrational Spectroscopy, 24, 2000, 213-224.

9- J. Clarkson, S.M Mason, K.P.J. Williams. Spectrochimica Acta, 1991, 47, 1345-1351.

10- T. Lazaridis, Acc. Chem. Res., 2001, 34, 931.

11- R. Signer, J. Weiler, Raman spectra and constitution of compounds of high molecular weight. LXII. Formation of higher polymers, Chim. Acta, 1932, 15, 649-657.

12- N. Sajai, A. Chahine, M. Et-tabirou, M. Taibi, A. Mazzah, Structure and properties of (50x) $\mathrm{CaO}-\mathrm{xPbO}-50 \mathrm{P}_{2} \mathrm{O}_{5}$ metaphosphate glasses, Optoelectronics and Advanced Materiels, 2012, 6, 99-103.

13- X. Li, A. Lu, H. Yang, Structure of ZnO$\mathrm{Fe}_{2} \mathrm{O}_{3}-\mathrm{P}_{2} \mathrm{O}_{5}$ glasses probed by Raman and IR spectroscopy, Journal of Non-Crystalline Solids. 2014, 389, 21-27.

14- J. A. Jiménez, M. Sendova. Catalyst role of $\mathrm{Nd}^{3+}$ ions for the precipitation of silver nanoparticles in phosphate glass, Journal of Alloys and Compounds. 2017, 691, 44-50.

15- R.F. Brandão, R.L. Quirino, V.M. Mello, A.P. Tavares, A.C. Peres, F. Guinhos, J.C. Rubim, P.A.Z Suarez, Synthesis, characterization and use of $\mathrm{Nb}_{2} \mathrm{O}_{5}$ based catalysts in producing biofuels by transesterification, esterification and pyrolysis, J. Braz. Chem. Soc. 2009, 20, 954-966.

16- S. Nasri, M. Megdiche, M. Gargouri, The investigation of dielectric properties and ac conductivity of new ceramic diphosphate $\mathrm{Ag}_{0.6} \mathrm{Na}_{0.4} \mathrm{FeP}_{2} \mathrm{O}_{7}$ using impedance spectroscopy method, Physica E: Lowdimensional Systems and Nanostructures.2016, 84, 182-190.

17- J.C. Ma and D.A. Dougherty, The Cation- $-\pi$ Interaction, Chem. Rev. 1997, 97, 1303-1324.

18- E.H. Agung, S.M. Sapuan, M.M. Hamdan, H.M.D.K. Zaman and U. Mustafa, Study on abaca (Musa textilis Nee) fibre reinforced high impact polystyrene (HIPS) composites by thermogravimetric analysis (TGA), International Journal of the Physical Sciences. 2011, 6, 2100-2106.

19- N. Rami, H. Meghraoui, A. Elharfi, Ann. Chim. Sci. Mat. 2009, 33, 479.

20- H.Y. Ma, Z.P. Fang, Synthesis and carbonization chemistry of a phosphorousnitrogen based intumescent flame retardant, Thermochim Act. 2012, 543, 130-136.

21- R. Escribano, J.J. Sloan, N. Siddique, N. Sze, T. Dudev, Raman spectroscopy of carboncontaining particles, Vibrational Spectroscopy. 2001, 26, 179-186.

22- S. Khatibi, M. Ostadhassan, A. Aghajanpour, Journal of Oil, Gas and Petrochemical Sciences. 2018, 1(1), 28-33.

23- S. Prawer, R. Nemanich, J. Raman spectroscopy of diamond and doped diamond, Phil. Trans. R. Soc. Lond. A. 2004, 362, 2537.

24- A.C. Ferrari, J. Robertson, Origin of the $1150-\mathrm{cm}^{-1}$ Raman mode in nanocrystalline diamond, Phys. Rev B. 2001, 63, 121405.

25- S. Song, J. Ma, K. Cao, G. Chang, Y. Huang, J. Yang, Synthesis of a novel dicyclic silicon/phosphorus hybrid and its performance on flame retardancy of epoxy resin, Polymer Degradation and Stability. 2014, 99, 43-52. 